
analysis of the Virginia phosphorus index management tool," Transactions of the ASAE. Vol. 48(5): 1773-1781. (doi: 10.13031/2013.20011)@2005

\title{
SENSITIVITy ANALYSis OF THE ViRginia Phosphorus Index Management Tool
}

\author{
J. B. Jesiek, M. L. Wolfe
}

\begin{abstract}
The phosphorus index (P-Index) is a risk assessment and management tool to aid in reducing the risk to water quality due to movement of excess phosphorus $(P)$ from fields. An allowable $P$ application rate is specified based on the computed risk. This study focused on the Virginia P-Index. The objectives were to determine the factors to which the P-Index is most sensitive and to determine the factors to which the resulting $P$ application rate recommendations are most sensitive. A differential analysis was used to calculate relative sensitivity for nine baseline scenarios: a low, medium, and high baseline within three different regions of Virginia. Impact of user variability in estimating factor values was evaluated using a probability distribution analysis. The P-Index was most sensitive in the low and medium baseline scenarios to P management factors, including annual application rate, method of fertilizer application, and source availability factor. In high-risk baseline scenarios, the P-Index was most sensitive to transport factors (erosion, runoff, or leaching). User variability had a greater impact on the $P$-Index and on $P$ application rate recommendations as $P$ risk increased over each of the three regions. The closer a field's $P$-Index value is to a threshold between $P$ recommendation rate categories, the higher the probability that alternate $P$ application rates will be recommended due to user variability. The results highlight the need for consistent estimation of factor values, particularly the factors to which the P-Index is most sensitive and particularly in the higher-risk situations.
\end{abstract}

Keywords. Nutrient management, Phosphorus management, Sensitivity analysis.

$\mathrm{P}$ hosphorus $(\mathrm{P})$ is widely applied in crop and pasture systems as an essential nutrient for crop growth. It is well documented that applying fertilizer $P$ will increase crop yields in soil that is low in P. However, application of $\mathrm{P}$ in excess of crop requirements can cause $\mathrm{P}$ buildup in soils. Phosphorus buildup in soils has occurred mainly in areas where animal manures have been applied to crops and pastures based on nitrogen $(\mathrm{N})$ requirements of crops. This can lead to excess $\mathrm{P}$ in the soil since the N:P ratio is much lower in animal manures than that required by most crops. A general consensus in the past was that $\mathrm{P}$ was stable in the soil system as long as soil erosion was minimized. However, recent studies have shown that soil high in $\mathrm{P}$ is more susceptible to runoff and leaching losses (Sharpley et al., 1994; Daniel et al., 1994). Excess P that is transported into water bodies can cause water quality problems, including eutrophication.

Phosphorus soil tests have long been used to determine plant-available P in soils. Studies have shown that there is a relationship between soil test $\mathrm{P}$ and $\mathrm{P}$ in runoff (Sharpley, 1995; Pautler and Sims, 2000; Pote et al., 1996). However, a high soil test $\mathrm{P}$ does not necessarily mean there is a high

Article was submitted for review in January 2005; approved for publication by the Soil \& Water Division of ASABE in July 2005. Presented at the 2003 ASAE Annual Meeting as Paper No. 032156.

The authors are Julie B. Jesiek, ASABE Member Engineer, Research Associate, and Mary Leigh Wolfe, ASABE Member Engineer, Associate Professor, Department of Biological Systems Engineering, Virginia Tech, Blacksburg, Virginia. Corresponding author: Mary Leigh Wolfe, Department of Biological Systems Engineering (0303), Virginia Tech, Blacksburg, VA 24061, phone: 540-231-6092; fax: 540-231-3199; e-mail: mlwolfe@vt.edu. probability of $\mathrm{P}$ loss from a particular field. A high potential for $\mathrm{P}$ loss occurs when there is a high transport potential from erosion, runoff, and/or leaching coupled with high soil test $\mathrm{P}$ and/or other source of $\mathrm{P}$ such as fertilizer (Gburek et al., 2000).

Phosphorus management tools can aid in improving water quality. A management tool that could identify areas with a high potential for $\mathrm{P}$ loss is desirable. These areas can then be targeted and management practices implemented to decrease the overall P loss. The P-Index is such a tool, developed by the USDA Natural Resources Conservation Service (NRCS) as a field-level assessment tool that integrates soil, management, environmental, and hydrologic characteristics to determine the risk of P loss to surface water (USDA-SCS, 1994; Lemunyon and Gilbert, 1993). Forty-seven states have adopted the P-Index approach for nutrient management planning (Sharpley et al., 2003).

\section{BACKGROUND \\ Virginia PhosPhorus INDEX}

A multidisciplinary team at Virginia Tech has developed a P-Index for Virginia. It is a mass-based tool that estimates the annual risk of delivery of $\mathrm{P}$ to surface water from a given field. The Virginia P-Index was developed to facilitate management of $P$ in an environmentally sound manner. The objective of managing $\mathrm{P}$ applications based on the P-Index is to reduce the risk of $\mathrm{P}$ being lost from fields and delivered to surface waters, thus reducing potential water quality problems due to excess P.

The P-Index includes site-specific erosion, runoff, fertilizer, and subsurface risk factors to estimate the P delivery risk to surface water. Source and transport factors included in the 
index were determined based on data collected on selected Virginia soils, published literature, and the professional judgment of the P-Index development team (Mullins et al., 2005).

The Virginia P-Index is calculated as follows:

$$
\begin{aligned}
\text { PRisk } & =\left[\left(S L * D_{S E D} * T P_{S E D}\right)\right. \\
& +\left(R O * D_{R O} * D R P_{R O}\right) \\
& \left.+D R P_{F E R T}+\left(\operatorname{Perc}^{*} S F * D R P_{S U B}\right)\right]
\end{aligned}
$$

where

$$
\begin{aligned}
& \text { PRisk } \quad=\mathrm{P} \text { delivery risk to surface water }(\mathrm{kg} / \mathrm{ha}) \\
& S L \quad \text { = edge of field soil loss (million } \mathrm{kg} / \mathrm{ha} \text { ) } \\
& D_{S E D} \quad=\text { sediment } \mathrm{P} \text { delivery factor (dimensionless) } \\
& T P_{S E D}=\text { sediment total } \mathrm{P} \text { factor }(\mathrm{ppm}) \\
& R O=\text { runoff from field (million } \mathrm{kg} / \mathrm{ha} \text { ) } \\
& D_{R O} \quad=\text { runoff } \mathrm{P} \text { delivery factor (dimensionless) } \\
& D R P_{R O}=\text { runoff dissolved reactive orthophosphate } \\
& \text { (DRP) factor (ppm) } \\
& D R P_{F E R T}=\text { factor for planned applied fertilizer DRP } \\
& \text { (kg/ha) } \\
& \text { Perc = percolation }(\text { million } \mathrm{kg} / \mathrm{ha}) \\
& S F \quad=\text { soil texture/drainage factor (dimensionless) } \\
& D R P_{S U B}=\text { subsurface DRP factor (ppm). }
\end{aligned}
$$

The first term on the right side of equation 1 represents the $\mathrm{P}$ delivery risk due to erosion. The second term represents the risk due to runoff. The third term represents the risk due to fertilizer application. The fourth term represents the risk due to leaching.

The purpose of the P-Index is to aid in $\mathrm{P}$ management to minimize delivery of $\mathrm{P}$ to surface waters. The P-Index is calculated based on the planned crops, management practices, and $\mathrm{P}$ application rates. For management of $\mathrm{P}$, the resulting value of the $\mathrm{P}$-Index is translated into a recommended maximum $\mathrm{P}$ application rate (table 1). The planned rate cannot exceed the rate recommended by the P-Index.

The recommended rates are based on the potential water quality impact as expressed by risk of delivery of $\mathrm{P}$ from a field to surface water. If the risk is low (P-Index $\leq 30)$, then $\mathrm{P}$ can be applied at the rate that corresponds to applying manure/biosolids based on the $\mathrm{N}$ requirements of the crop (N-based recommendation). If the potential water quality impact is medium or high, the $\mathrm{P}$ application rate should be based on the $\mathrm{P}$ needs of the crop (P-based recommendation). Two different $\mathrm{P}$-based rates are included (crop removal and 1.5 times crop removal) depending on the level of risk.

Table 1. Summary interpretation of the Virginia P-Index.

\begin{tabular}{ccl}
\hline $\begin{array}{c}\text { P-Index } \\
\text { Value } \\
(\text { PRisk } \times 6.3)^{[a]}\end{array}$ & $\begin{array}{c}\text { Potential } \\
\text { Water Quality } \\
\text { Impact }\end{array}$ & $\begin{array}{l}\text { Phosphorus Management Guidance } \\
\text { Based on Proposed Management } \\
\text { Practices }\end{array}$ \\
\hline $0-30$ & Low & $\begin{array}{l}\text { Phosphorus applications according to } \\
\text { N-based nutrient management are ac- } \\
\text { ceptable. }\end{array}$ \\
\hline $31-60$ & Medium & $\begin{array}{l}\text { Phosphorus applications should not be } \\
\text { greater than 1.5 times crop removal. }\end{array}$ \\
\hline $61-100$ & High & $\begin{array}{l}\text { Phosphorus applications should not be } \\
\text { greater than crop removal. }\end{array}$ \\
\hline$>100$ & Very high & \begin{tabular}{l} 
No phosphorus should be applied. \\
\hline [a]
\end{tabular} \\
$\begin{array}{l}\text { The result of equation 1 is multiplied by 6.3 to obtain the P-Index value } \\
\text { to use in this table. The scaling factor expands the P-Index scale such } \\
\text { that the threshold for the very high category is 100; this threshold is con- } \\
\text { sistent with other P-indexes in the mid-Atlantic states. }\end{array}$
\end{tabular}

Finally, if the risk is very high, no $\mathrm{P}$ should be applied to the field.

Virginia Department of Conservation and Recreation (DCR) and USDA-NRCS personnel, as well as private-sector nutrient management planners, are applying the P-Index in Virginia. DCR-employed and private DCR-certified nutrient management planners will apply the P-Index as specified in regulations (Proposed Nutrient Management Training and Certification Regulations) currently open for public comment. NRCS personnel are applying the P-Index to fields as specified by the Virginia practice standard for nutrient management (USDA-NRCS-VA, 2001).

Errors or lack of consistency in recommended P application rates can have significant impact on both the farmer and the regulator. For P-based rates, less manure can be applied than with $\mathrm{N}$-based rates, making it necessary for the farmer to purchase additional $\mathrm{N}$ fertilizer and increasing costs for the farmer. In addition, for a farm with a smaller land base, moving from $\mathrm{N}$-based rates through the P-based rates could result in excess manure on the farm, which would have to be utilized offsite, most likely via transport to another farm. This could be quite costly, especially for a dairy or swine facility with liquid manure. For the regulator, consistency within the recommendations is important to strengthen the tool so that the "wrong" recommendation is not given.

To ensure consistent recommendations based on the P-Index, the value of each factor within the P-Index must be estimated consistently. Because some nutrient management planners find some of the factors more difficult to estimate than others, training of field staff should emphasize the factors most prone to variability in estimation. The factors to which the P-Index and subsequent $\mathrm{P}$ application recommendations are the most sensitive should also be emphasized in training and application.

The objectives of this study were: (1) to determine the factors to which the P-Index value is most sensitive, and (2) to determine the factors to which the P-Index-based $\mathrm{P}$ application rate recommendations are most sensitive. The results of the research will also be used to help identify P-Index factors on which future research and development should focus to improve estimates of the P delivery risk to surface waters.

\section{Sensitivity Analysis}

Sensitivity analysis is the general term used to describe analyses conducted to determine variables to which a model is sensitive. Sensitivity analysis techniques can be grouped into two categories: deterministic, or single-variable, and stochastic. In the deterministic or single-variable approach, only one value is given for each input parameter and the analysis is for one scenario. Various techniques have been developed to quantify sensitivity of the model using the deterministic approach. The most basic method is differential analysis, or the direct method, determined from simple partial derivatives (Morisawa and Inoue, 1974; Dickinson and Gelinas, 1976; Helton et al., 1985). When solving the partial differential is not possible, relative sensitivity can also be calculated for any point, as defined by James and Burges (1982):

$$
S_{r}=\frac{\partial R}{\partial P} \frac{P}{R} \quad \text { or } \quad S_{r}=\frac{\left(R-R_{b}\right)}{\left(P-P_{b}\right)} \frac{P_{b}}{R_{b}}
$$


where $S_{r}$ is relative sensitivity, $R$ is the result or output, $P$ is the model input parameter, and subscript $b$ indicates values of the base scenario.

Model sensitivity can be evaluated by ranking parameters from resultant output changes or by developing criteria to characterize parameter sensitivity. Another way to quantify sensitivity is the sensitivity index, or the percent difference in output when varying one input parameter from its minimum value to its maximum value (Hoffman and Gardner, 1983):

$$
\mathrm{SI}=\frac{D_{\max }-D_{\min }}{D_{\max }}
$$

where SI is the sensitivity index, and $D_{\min }$ and $D_{\max }$ represent the minimum and maximum output values, respectively. Hoffman and Gardner (1983) advocated utilizing each parameter's entire range of possible values in order to assess true parameter sensitivities.

In contrast to a deterministic approach, a stochastic sensitivity analysis is used when there is uncertainty in the values of various parameter inputs. A stochastic sensitivity analysis assesses the effect a parameter has on an output variable over the range of parameter values that are likely to be exhibited. The stochastic sensitivity analysis attempts to partition the variance observed in the output variable to multiple parameters (Renard and Ferreira, 1993). Quantification in a stochastic sensitivity analysis is performed using random sampling methods such as Monte Carlo or Latin hypercube to generate input and output distributions (Hamby, 1994).

Sensitivity analyses have been conducted for a range of nonpoint-source pollution models using various methods and techniques. For example, deterministic analyses have been conducted of the Environmental Policy Integrated Climate (EPIC) model (Roloff et al., 1998), the Hydrological
Simulation Program-FORTRAN (HSPF) (Jacomino and Fields, 1997), and the Root Zone Water Quality Model (RZWQM) (Walker et al., 2000). Tiscareno-Lopez (1991) conducted a stochastic sensitivity analysis of the Water Erosion Prediction Project (WEPP). Although sensitivity analysis techniques have been widely applied in agricultural hydrologic modeling, these models tend to be more complex than a simple index. Sensitivity analysis techniques have not been widely applied to more simplistic, mixed-variable, agricultural indexes, such as the Virginia P-Index. Thus, the analysis conducted and described in this study represents an original application that could be applicable to other mixed-variable indexes and simple models. The deterministic approach using the direct method to calculate relative sensitivity was used in the baseline sensitivity analysis. The stochastic approach using the Latin hypercube sampling method was used to evaluate P-Index inputs that are subject to estimation variability by users.

\section{Procedures}

The outputs of interest in the sensitivity analysis, as stated in the project objectives, were the P-Index value and the $\mathrm{P}$ management guidance. The analysis was completed for all of the inputs listed in table 2. The third column of table 2 indicates the basic input parameters on which each factor was based. The input parameters of interest were determined to be soil loss, distance to stream, Mehlich I soil test P (Mehlich, 1953), curve number, the planned $P$ application rate, type of fertilizer, and application method. In addition, the soil texture/drainage class factor was of interest in scenarios for which the baseline value of that factor was non-zero.

Sensitivity of the P-Index output to inputs was determined based on three baseline scenarios for each of three regions: Ridge and Valley, Piedmont, and Eastern Shore (fig. 1).

Table 2 Erosion, runoff, management, and subsurface factors used in the Virginia P-Index (Mullins et al., 2005).

\begin{tabular}{|c|c|c|}
\hline Factors & Equation/Method of Determination & Basic Input Subfactor Parameters \\
\hline Erosion Risk & Multiply the three listed factors. & \\
\hline Edge of field soil loss $(S L)$ & Revised Universal Soil Loss Equation (RUSLE) or (RUSLE2). & Soil loss \\
\hline Sediment $\mathrm{P}$ delivery factor $\left(D_{S E D}\right)$ & $\begin{array}{l}\text { Table relating riparian buffer width and/or distance from edge of } \\
\text { field to intermittent or perennial stream. }\end{array}$ & $\begin{array}{l}\text { Distance to stream and riparian } \\
\text { buffer width }\end{array}$ \\
\hline Sediment total $\mathrm{P}$ factor $\left(T P_{S E D}\right)$ & Regression equation; function of Mehlich I soil test P. & Mehlich I soil test P \\
\hline Runoff Risk & Multiply the three listed factors. & \\
\hline Runoff from field $(R O)$ & $\begin{array}{l}\text { NRCS runoff curve number method applied to historic distribution } \\
\text { of daily rainfall events in } 0.1 \text { in. increments; daily runoff then } \\
\text { summed to estimate average annual runoff (based on climatic } \\
\text { zone). }\end{array}$ & Curve number $(\mathrm{CN})$ \\
\hline Runoff $\mathrm{P}$ delivery factor $\left(D_{R O}\right)$ & $\begin{array}{l}\text { Table relating riparian buffer width and distance from edge of } \\
\text { field to intermittent or perennial stream. }\end{array}$ & $\begin{array}{l}\text { Distance to stream and riparian } \\
\text { buffer width }\end{array}$ \\
\hline $\begin{array}{l}\text { Runoff DRP (dissolved reactive } \\
\text { orthophosphate) factor }\left(D R P_{R O}\right)\end{array}$ & Regression equation; function of Mehlich I soil test P. & Mehlich I soil test P \\
\hline Management Risk & Equals the listed factor. & \\
\hline $\begin{array}{l}\text { Applied fertilizer DRP factor } \\
\left(D R P_{F E R T}\right)\end{array}$ & $\begin{array}{l}\text { Multiply rate of } \mathrm{P} \text { application by factors given in tables of avail- } \\
\text { ability of } \mathrm{P} \text { in applied source and method of } \mathrm{P} \text { fertilizer applica- } \\
\text { tion. }\end{array}$ & $\begin{array}{l}\text { P application rate, type of fertilizer, } \\
\text { application method }\end{array}$ \\
\hline Subsurface Risk & Multiply the listed factors. & \\
\hline Percolation (Perc) & $\begin{array}{l}\text { Determined from annual rainfall, runoff from field, and estimated } \\
\text { evapotranspiration. }\end{array}$ & Curve number $(\mathrm{CN})$ \\
\hline $\begin{array}{l}\text { Soil texture/drainage class factor } \\
(S F)\end{array}$ & $\begin{array}{l}\text { Table relating value to soil drainage class (NRCS) and soil texture } \\
\text { to a soil depth of } 46 \mathrm{~cm} .\end{array}$ & $\begin{array}{l}\text { Soil drainage class and soil texture } \\
\text { to a depth of } 46 \mathrm{~cm}\end{array}$ \\
\hline Subsurface DRP factor $\left(D R P_{S U B}\right)$ & Regression equation; function of Mehlich I soil test P. & Mehlich I soil test P \\
\hline
\end{tabular}




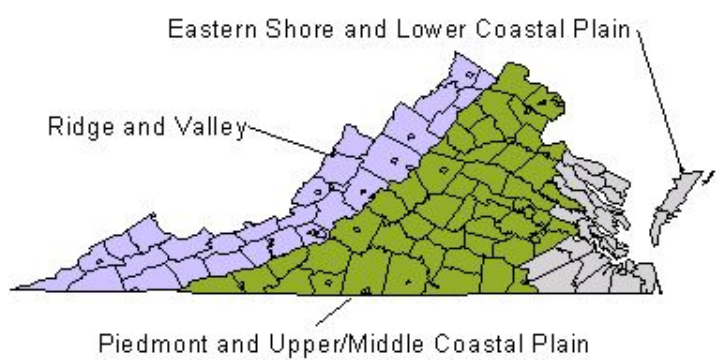

Figure 1. Physiographic regions of Virginia used with the Virginia Pindex (Mullins et al., 2005).

Baseline scenarios were based on typical field characteristics for each region (table 3), including crop rotations, soil textures and drainage classes, and management practices. Three baseline scenarios were developed for each region, corresponding to low, medium, and high risk of $\mathrm{P}$ delivery to surface water. The emphasis in baseline scenario selection was on representing typical field characteristics in each region rather than on representing a wide range of values for each subfactor and factor. Thus, the baseline values (table 4) of some inputs included a narrow range of values due to predominant conditions within the regions.

A deterministic sensitivity analysis approach was used with one input varied at a time, and relative sensitivity was calculated as defined by James and Burges (1982). Specifically, the P-Index (eq. 1) was differentiated with respect to the parameter of interest for all parameters except curve number and distance to stream. The P-Index is not directly differentiable with respect to those two parameters, so relative sensitivity was calculated by varying each parameter $\pm 15 \%$ and $35 \%$; distance to stream was also varied within categories from its base value. The percentages were selected to encompass the likely range of values of the parameters. Categories for relative sensitivity were defined as used by Storm et al. (1986): insensitive $\left(S_{r}<|0.01|\right)$, slightly sensitive $\left(|0.01| \leq S_{r}<|0.10|\right)$, moderately sensitive $\left(|0.10| \leq S_{r}<|1.00|\right)$, sensitive $\left(|1.00| \leq S_{r}<|2.00|\right)$, and extremely sensitive $\left(S_{r} \geq|2.00|\right)$.

Average annual soil loss, distance to stream, and Mehlich I soil test $\mathrm{P}$ are the input parameters whose estimated values are most variable among users. Variability in average annual soil loss calculations using RUSLE are commonly caused by variation in estimates of soil length and steepness (USDA-NRCS-VA, 1997). Estimates of distance to stream can vary among users due to assessment of flow direction and definition of "stream." Subjectivity in soil sampling, including selection of location and number of sampling sites, can lead to variability in soil test $\mathrm{P}$ values for fields.

The best way to quantify the extent of variability would be to have many different users estimate the parameter values for a variety of fields. Those values could then be analyzed statistically to determine the range and distribution of values for each parameter. This was not possible due to timing and financial constraints, and due to the fact that the P-Index has not yet been widely applied. Instead, probability distributions were defined for the most variable input subfactors (average annual soil loss, distance to stream, and Mehlich I soil test P) based on a review of published values and professional judgment.

A truncated triangular distribution was used to represent the variability of soil loss based on ranges of annual soil loss using RUSLE from estimated values for the LS factor when the slope was varied $\pm 1.0 \%$ and slope length was varied $\pm 15 \mathrm{~m}$ from the baseline. This distribution was chosen to place a higher probability on the baseline value, which would more likely be chosen by the user. The distribution was truncated based on judgment of reasonable high and low values for soil loss. In the example shown in figure 2, the resulting truncated distribution was nearly symmetrical. In a triangular distribution, the most likely value is chosen 1.5 times more than the other values (Palisade Corp., 2000).

Table 3. Baseline scenario characteristics.

\begin{tabular}{|c|c|c|c|}
\hline Region & Low P Delivery Risk Scenario & Medium P Delivery Risk Scenario & High P Delivery Risk Scenario \\
\hline Ridge and valley & $\begin{array}{l}\text { Hay with inorganic fertilizer, } 6 \% \\
\text { slope, silt loam, hydrologic group } \\
\text { B, well drained. }\end{array}$ & $\begin{array}{l}\text { Corn/small grain rotation, no-till } \\
\text { corn, poultry litter applied, } 4 \% \text { slope, } \\
\text { silt loam, hydrologic group B, mod- } \\
\text { erately to well drained. }\end{array}$ & $\begin{array}{l}\text { Corn with conventional tillage, dairy } \\
\text { manure applied, } 5 \% \text { slope, silt loam, } \\
\text { hydrologic group B, moderately to } \\
\text { well drained. }\end{array}$ \\
\hline $\begin{array}{l}\text { Piedmont and middle/up- } \\
\text { per coastal plain }\end{array}$ & $\begin{array}{l}\text { Hay with inorganic fertilizer, } 4 \% \\
\text { slope, silt loam, hydrologic group } \\
\text { B, well drained. }\end{array}$ & $\begin{array}{l}\text { Corn/small grain rotation, no-till } \\
\text { corn, poultry litter applied, } 6 \% \text { slope, } \\
\text { silt loam, hydrologic group B, mod- } \\
\text { erately to well drained. }\end{array}$ & $\begin{array}{l}\text { Corn, conventional tillage, dairy ma- } \\
\text { nure applied, } 6 \% \text { slope, silt loam, } \\
\text { hydrologic group B, moderately to } \\
\text { well drained. }\end{array}$ \\
\hline $\begin{array}{l}\text { Eastern shore and lower } \\
\text { coastal plain }\end{array}$ & $\begin{array}{l}\text { Corn/bean rotation w/cover, inor- } \\
\text { ganic fertilizer, } 0.5 \% \text { slope, sandy } \\
\text { loam, hydrologic group B, well } \\
\text { drained. }\end{array}$ & $\begin{array}{l}\text { Corn/small grain rotation, no-till } \\
\text { corn, poultry litter applied, } 1 \% \text { slope, } \\
\text { fine sandy loam, hydrologic group C, } \\
\text { somewhat poorly drained. }\end{array}$ & $\begin{array}{l}\text { Corn, conventional tillage, poultry lit- } \\
\text { ter applied, } 2 \% \text { slope, sandy loam, } \\
\text { hydrologic group D, poorly drained. }\end{array}$ \\
\hline
\end{tabular}

Table 4. P delivery risk baseline scenario factors for the three regions.

\begin{tabular}{|c|c|c|c|c|c|c|c|c|c|}
\hline \multirow[b]{3}{*}{ Baseline Factors } & \multicolumn{3}{|c|}{ Ridge and Valley } & \multicolumn{3}{|c|}{ Piedmont } & \multicolumn{3}{|c|}{ Eastern Shore } \\
\hline & \multicolumn{3}{|c|}{ P Delivery Risk } & \multicolumn{3}{|c|}{ P Delivery Risk } & \multicolumn{3}{|c|}{ P Delivery Risk } \\
\hline & Low & Medium & High & Low & Medium & High & Low & Medium & High \\
\hline Annual soil loss (t/ha) & 0.3 & 5.2 & 10.1 & 0.5 & 5.4 & 9.6 & 0.02 & 0.5 & 3.4 \\
\hline Mehlich I soil test P (ppm) & 30 & 175 & 400 & 30 & 175 & 350 & 30 & 75 & 125 \\
\hline Distance to stream (m) & 125 & 85 & 70 & 125 & 90 & 45 & 125 & 30 & 4 \\
\hline Soil texture/drainage class & 0 & 0 & 0 & 0 & 0 & 0 & 0 & 0.25 & 0.75 \\
\hline Curve number $(\mathrm{CN})$ & 58 & 75 & 78 & 58 & 75 & 75 & 72 & 78 & 89 \\
\hline $\mathrm{P}$ application rate $(\mathrm{kg} / \mathrm{ha})$ & 48 & 106 & 117 & 48 & 106 & 117 & 48 & 106 & 117 \\
\hline P-Index & 14 & 46 & 89 & 14 & 41 & 79 & 14 & 42 & $101^{[\mathrm{a}]}$ \\
\hline
\end{tabular}

[a] P-Index output for this scenario is within the very high management category recommendation. 


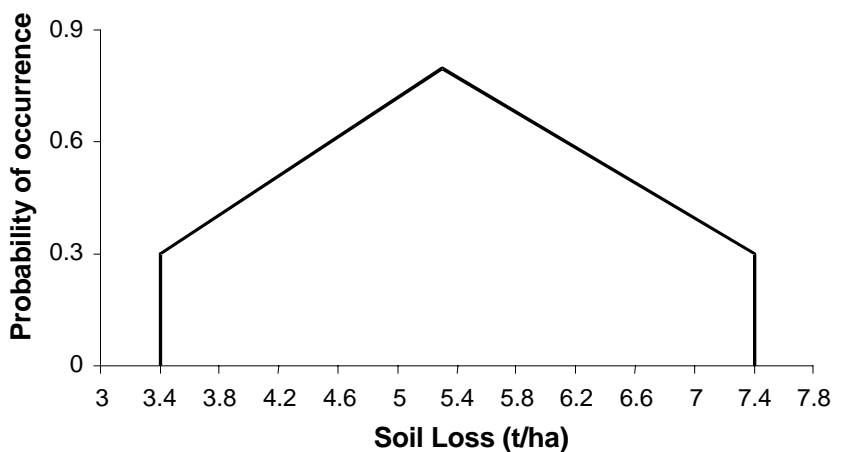

Figure 2. Truncated triangular distribution for soil loss within the Ridge and Valley medium $\mathbf{P}$ delivery risk scenario.

A discrete distribution was used to represent the variability of distance to stream to represent the step function, as shown in figure 3 for the sediment delivery factor within the Ridge and Valley medium $\mathrm{P}$ delivery risk scenario. A lognormal distribution was used to represent the variability of soil test P based on published literature (Schmidt et al., 2002) (fig. 4).

The program @Risk (Palisade Corp., 2000), a risk analysis software package, was used to generate probability density functions of the P-Index as a function of the three input distributions. Baseline values were used for all other parameters. The Latin hypercube random sampling method within@Risk was used since it has been shown to produce better results than the Monte Carlo method (Palisade Corp., 2000). The resulting P-Index probability density functions

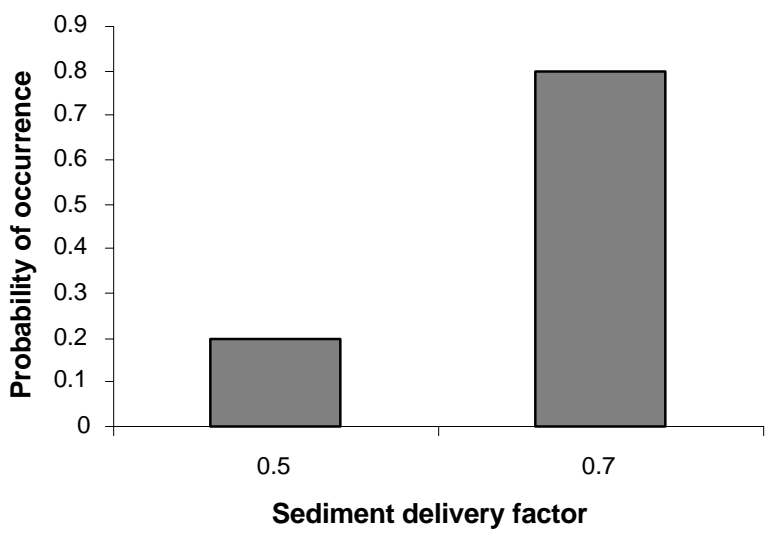

Figure 3. Discrete distribution for the sediment delivery factor within the Ridge and Valley medium $P$ delivery risk scenario.

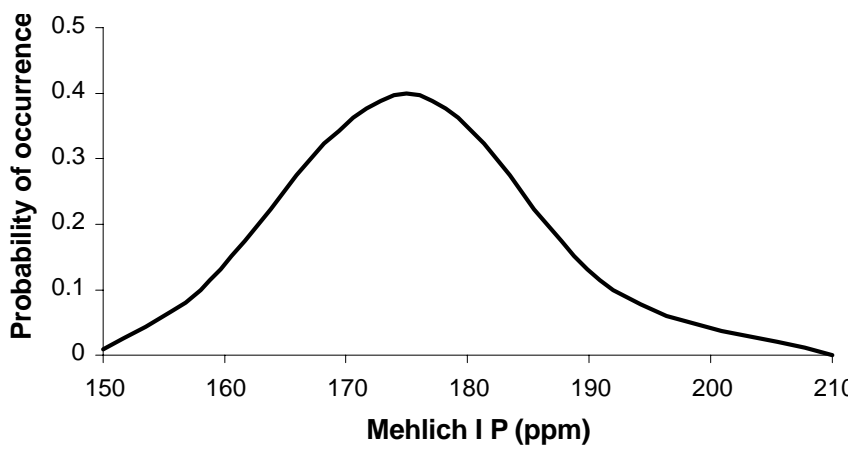

Figure 4. Lognormal distribution for Mehlich I soil test $P$ within the Ridge and Valley medium $P$ delivery risk scenario. were analyzed with respect to the range and distribution of values. The probability that the P-Index would be within each of the $\mathrm{P}$ management categories defined in table 1 was determined by integrating the probability density function over the range of P-Index values included in each category.

\section{RESULTS AND DisCUSSION}

Relative sensitivity of the P-Index to evaluated input factors is presented in figure 5 for all baseline scenarios in each of the three regions. Because the erosion risk factor is the product of three subfactors (eq. 1), the relative sensitivity of each subfactor is the same as that of the overall erosion risk factor. This occurs because the partial differential with respect to each subfactor is the product of the other two subfactors. The relative sensitivity is the product of the partial differential and the subfactor divided by the computed P-Index. Thus, for each subfactor, the relative sensitivity is the product of the three subfactors divided by the P-Index value. Similarly, the runoff risk factor, the applied fertilizer risk factor, and the subsurface risk factor are each the product of three subfactors. Relative sensitivity of the P-Index to each of the factors varied among the low, medium, and high $\mathrm{P}$ delivery risk scenarios within each of the regions, with the results more similar between the Ridge and Valley and Piedmont regions than compared to the Eastern Shore region. Sensitivity to the subsurface factor was apparent only in the Eastern Shore region medium and high $\mathrm{P}$ delivery risk scenarios because those were the only baselines with a non-zero subsurface risk value due to a non-zero soil texture/drainage class factor value (table 4).

The P-Index was most sensitive in the low and medium scenarios to the $\mathrm{P}$ management subfactors including annual application rate, method of fertilizer application, applied fertilizer DRP, and source availability factor (fig. 5). The P-Index was moderately sensitive to the erosion subfactors for the medium $\mathrm{P}$ delivery risk scenarios for the Ridge and Valley and Piedmont regions.

Relative sensitivity of the P-Index to the three input parameters most subject to estimation variability (soil loss, Mehlich I soil test P, and distance to stream) also varied among regions (fig. 6). Relative sensitivity to both soil loss and Mehlich I soil test P increased as the risk level increased. The sediment and runoff delivery subfactors are functions of distance to stream, e.g., the sediment delivery subfactor is equal to 1.0 if the distance to stream is less than $30 \mathrm{~m}$, while the subfactor value is 0.8 if the distance to stream is between 61 and $91 \mathrm{~m}$. A step function was used to relate these subfactors to ranges of distance to stream. The relative sensitivity of the P-Index to distance to stream was non-zero only when the baseline distances were near a category threshold.

In general, the relative sensitivity results appeared to be reasonable and consistent with known relationships. For example, the P-Index was insensitive to slightly sensitive to the runoff subfactor and moderately sensitive to the erosion risk factor (except for the Eastern Shore region, where the subsurface risk factor was non-zero). Typically, $\mathrm{P}$ loss associated with sediment is estimated to contribute $60 \%$ to $90 \%$ of P transported from cultivated land (Sharpley et al., 1992). Losses from dissolved $P$ in runoff are a concern typically in grass, pasture, and no-till cropping, where soil 


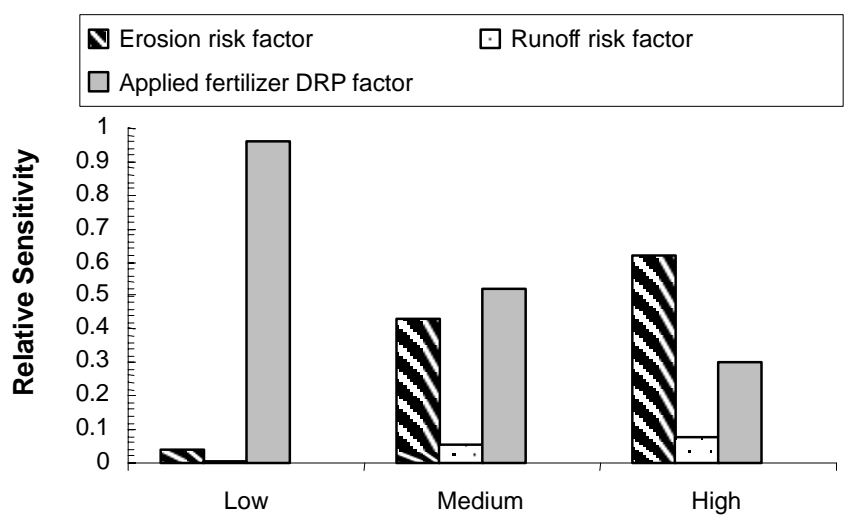

(a) Ridge and Valley region
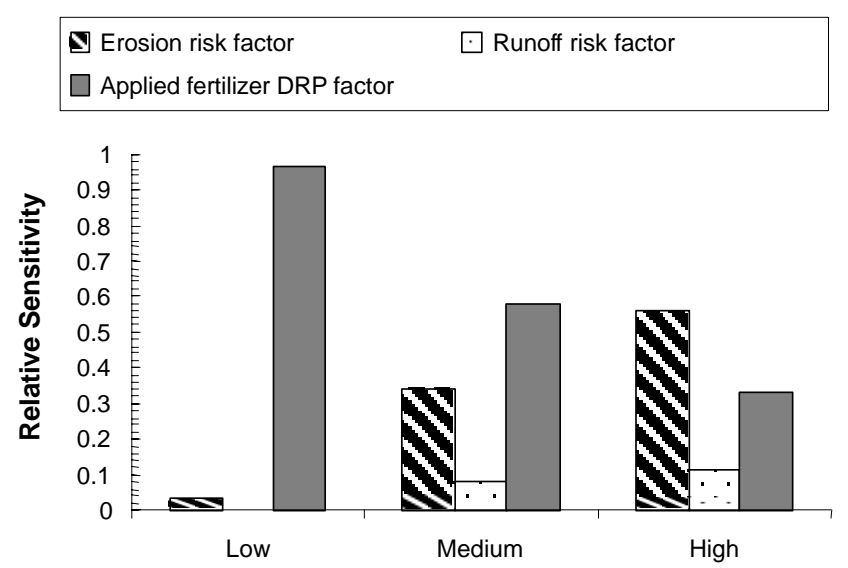

(b) Piedmont region

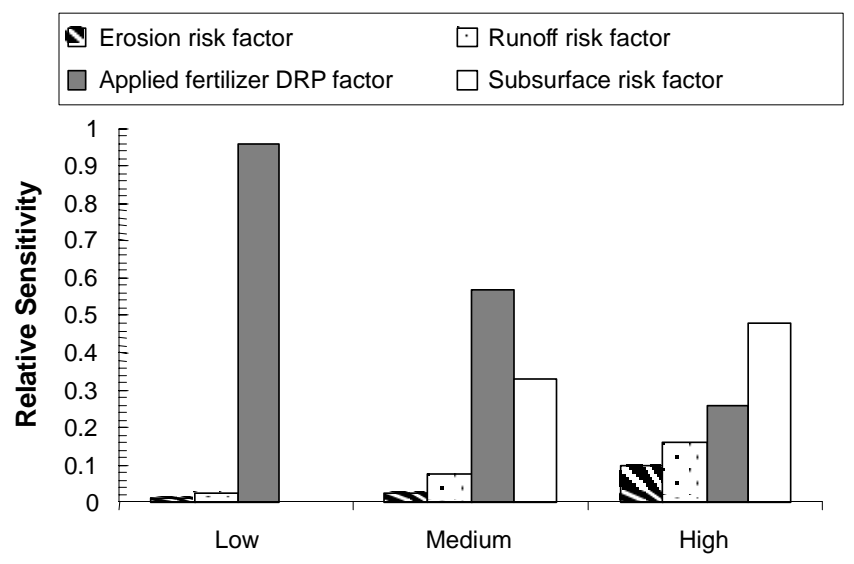

(c) Eastern Shore region

Figure 5. Relative sensitivity for risk factors for each of the baseline scenarios within the three physiographic regions of Virginia.

losses are lower than in conventional cropping systems. In no-till systems, higher concentrations of $\mathrm{P}$ might occur in runoff compared to conventional systems due to buildup of $\mathrm{P}$ in the surface layer (Andraski et al., 2003). In the medium $\mathrm{P}$ delivery risk scenarios, where no-till cropping was in place in fields across all regions, the P-Index risk was lower than might be expected. In the latest version of the P-Index, version 1.3, stratification of $\mathrm{P}$ in the surface layer for continuous no-till cropping systems is accounted for by multiplying the 0-10 cm depth Mehlich I extractable P concentration by 1.5 ,

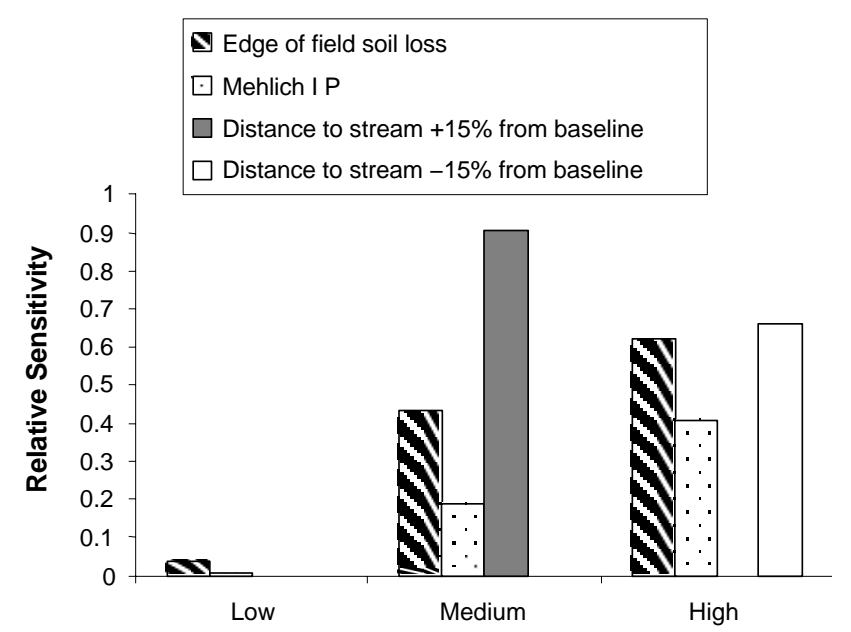

(a) Ridge and Valley region

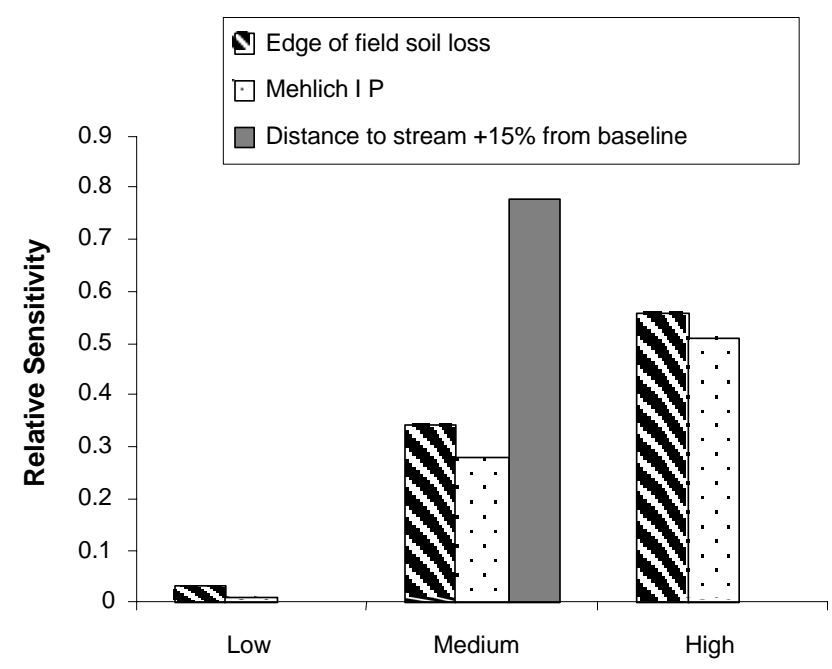

(b) Piedment region

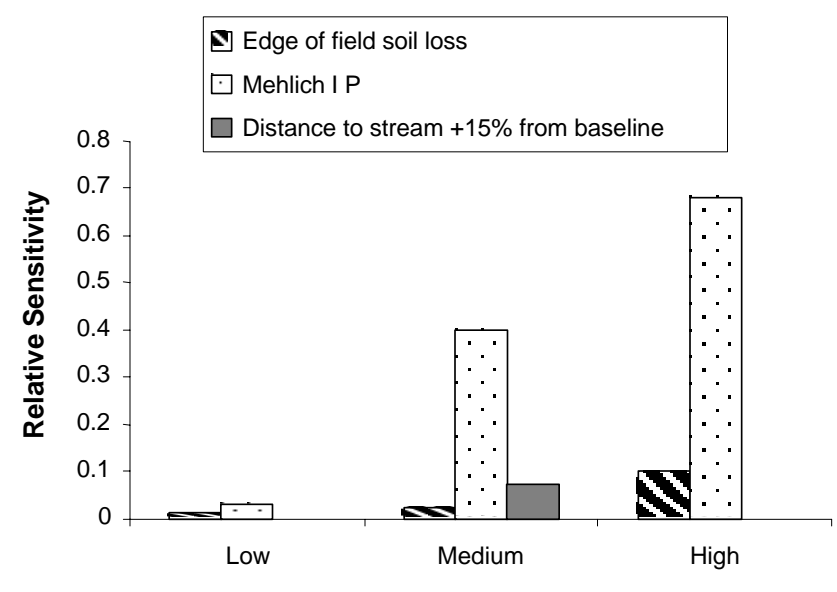

(c) Eastern Shore region

Figure 6. Relative sensitivity for soil loss, Mehlich I P, and distance to stream for each of the baseline scenarios within the three physiographic regions of Virginia.

thus increasing the amount of $\mathrm{P}$ available for runoff. The 1.5 factor was developed in another study based on soil samples collected at $0-2.5 \mathrm{~cm}$ and $0-10 \mathrm{~cm}$ depths. 
The P-Index was moderately sensitive to $\mathrm{P}$ application rate, which is part of the applied fertilizer DRP factor. In the P-Index equation, the amount of runoff does not affect the value of this factor, i.e., the applied fertilizer DRP factor is independent of the runoff risk factor. Thus, it is possible that the risk due to DRP from applied fertilizer is overemphasized in situations where there is little to no runoff. With little or no runoff, it would not be expected that a problematic amount of DRP would be transported from applied fertilizer to surface water. The $\mathrm{P}$ application rate recommendation based on the P-Index might be lower than such a low runoff situation would warrant. The formulation of the P-Index provides an environmentally conservative assessment of the risk due to applied fertilizer.

\section{Probability Distribution Analysis}

The potential variability of the inputs was represented by using distributions for distance to stream, Mehlich I P, and soil loss. With those distributions as inputs, the @ Risk software generated probability density functions of the P-Index (table 5). The probability density functions for the low, medium, and high $\mathrm{P}$ delivery risk scenarios for the Ridge and Valley region are shown in figure 7.

The results (table 5) show that variability defined by the input parameter distributions had a greater impact on the $\mathrm{P}$-Index as $\mathrm{P}$ risk increased over each of the three regions. Within the low $\mathrm{P}$ delivery risk scenarios, changes in the P-Index were minimal $(<1)$. The P-Index output for the medium $\mathrm{P}$ delivery risk scenarios varied by 7 to 20 units among the regions. Among the medium-risk scenarios, the P-Index for the Ridge and Valley region exhibited the greatest variability, with $90 \%$ of the distribution between 39 and 53 (fig. 7b).

Table 5. Summary of the P-Index probability density functions resulting from input distributions of three factors for the nine baseline scenarios.

\begin{tabular}{|c|c|c|c|c|c|c|c|c|}
\hline & & \multirow[b]{2}{*}{$\begin{array}{c}\text { Baseline } \\
\text { Output }\end{array}$} & \multicolumn{6}{|c|}{ P-Index Distribution } \\
\hline \multicolumn{2}{|c|}{ Baseline Scenario } & & Mean & Minimum & Maximum & $\begin{array}{l}\text { Standard } \\
\text { Deviation }\end{array}$ & $\begin{array}{c}5 \% \\
\text { Quantile }\end{array}$ & $\begin{array}{c}95 \% \\
\text { Quantile }\end{array}$ \\
\hline \multirow[t]{3}{*}{ Ridge and Valley } & Low risk & 14 & 14.2 & 14.0 & 14.5 & 0.1 & 14.1 & 14.4 \\
\hline & Medium risk & 46 & 45.6 & 35.3 & 55.3 & 4.4 & 38.7 & 53.1 \\
\hline & High risk & 89 & 93.1 & 71.2 & 120.6 & 11.0 & 76.3 & 111.3 \\
\hline \multirow[t]{3}{*}{ Piedmont } & Low risk & 14 & 14.0 & 13.8 & 14.3 & 0.1 & 13.9 & 14.2 \\
\hline & Medium risk & 41 & 39.6 & 32.3 & 47.8 & 3.5 & 34.3 & 46.0 \\
\hline & High risk & 79 & 80.3 & 61.8 & 101.3 & 9.3 & 65.2 & 95.9 \\
\hline \multirow[t]{3}{*}{ Eastern Shore } & Low risk & 14 & 14.2 & 13.9 & 14.5 & 0.1 & 14.0 & 14.4 \\
\hline & Medium risk & 42 & 41.8 & 38.5 & 45.3 & 4.2 & 40.0 & 43.8 \\
\hline & High risk & 101 & 101.7 & 89.7 & 115.3 & 5.0 & 94.9 & 108.5 \\
\hline
\end{tabular}

Table 6. Probability (\%) of being in each P management category for each baseline scenario.

\begin{tabular}{|c|c|c|c|c|c|c|}
\hline & & & & P Manag & Category & \\
\hline & Scenario & $\begin{array}{c}\text { Baseline } \\
\text { Output }\end{array}$ & $\begin{array}{l}\text { Low } \\
(0-30)\end{array}$ & $\underset{(31-60)}{\text { Medium }}$ & $\begin{array}{c}\text { High } \\
(61-100)\end{array}$ & $\begin{array}{l}\text { Very High } \\
(>100)\end{array}$ \\
\hline Ridge and Valley & Low $\mathrm{P}$ delivery risk & 14 & 100 & 0 & 0 & 0 \\
\hline & Medium $P$ delivery risk & 46 & 0 & 100 & 0 & 0 \\
\hline & High P delivery risk & 89 & 0 & 0 & 73 & 27 \\
\hline Piedmont & Low $\mathrm{P}$ delivery risk & 14 & 100 & 0 & 0 & 0 \\
\hline & Medium $P$ delivery risk & 41 & 0 & 1 & 0 & 0 \\
\hline & High P delivery risk & 79 & 0 & $>99$ & $<1$ & 0 \\
\hline Eastern Shore & Low $\mathrm{P}$ delivery risk & 14 & 100 & 0 & 0 & 0 \\
\hline & Medium $P$ delivery risk & 42 & 0 & 100 & 0 & 0 \\
\hline & High $\mathrm{P}$ delivery risk & 101 & 0 & 0 & 35 & 65 \\
\hline
\end{tabular}

The probability distribution analysis showed that variability in user-estimated values of Mehlich I P, soil loss, and distance to stream could result in a range of values for the $\mathrm{P}$-Index. This range of $\mathrm{P}$-Index values could result in recommendations in more than one $\mathrm{P}$ management category. The probability of being in each $\mathrm{P}$ management category for each baseline scenario was determined by integrating the probability distribution function over the values for each management category (table 6). For example, for the Ridge and Valley high $\mathrm{P}$ delivery risk scenario, integrating the probability density function from 61 to 100 yielded a value of 0.73 ; integrating the function from 100 to infinity yielded a value of 0.27 . Therefore, there was a $73 \%$ probability of being in the high $\mathrm{P}$ management category and a $27 \%$ probability of being in the very high $\mathrm{P}$ management category.

Since, in most of the scenarios, the baseline P-Index value was located near the middle of the management recommendations, there was not much change between management categories. The only scenarios that resulted in different $\mathrm{P}$ management categories were the high-risk scenarios for each region. If the baseline $\mathrm{P}$-Index value was within $5 \mathrm{P}$-Index rating units of the threshold value between the medium and high $\mathrm{P}$ management categories, there was up to a $16 \%$ probability of being in a different $\mathrm{P}$ management category. The probability increased for the switch from the high to very high category; if the baseline P-Index value was within 10 of the threshold between categories, there was up to $21 \%$ probability of being in a different $\mathrm{P}$ management category. Since the greatest variability in the P-Index occurs with high-risk scenarios (fig. 7), variations in $\mathrm{P}$ rate recommendations are more likely to occur among P-based rates rather than to cause a change between $\mathrm{N}$-based and P-based rates. 


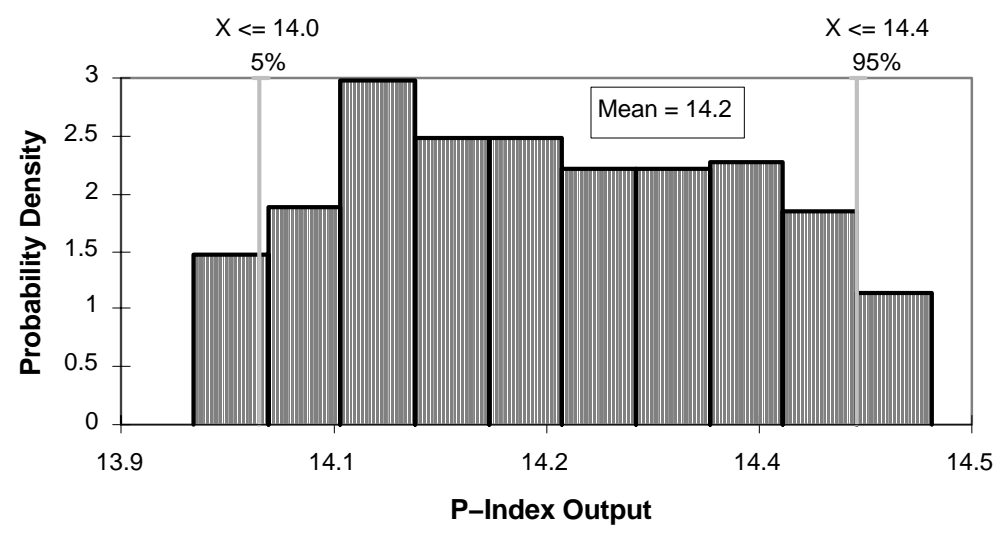

(a) Low P risk

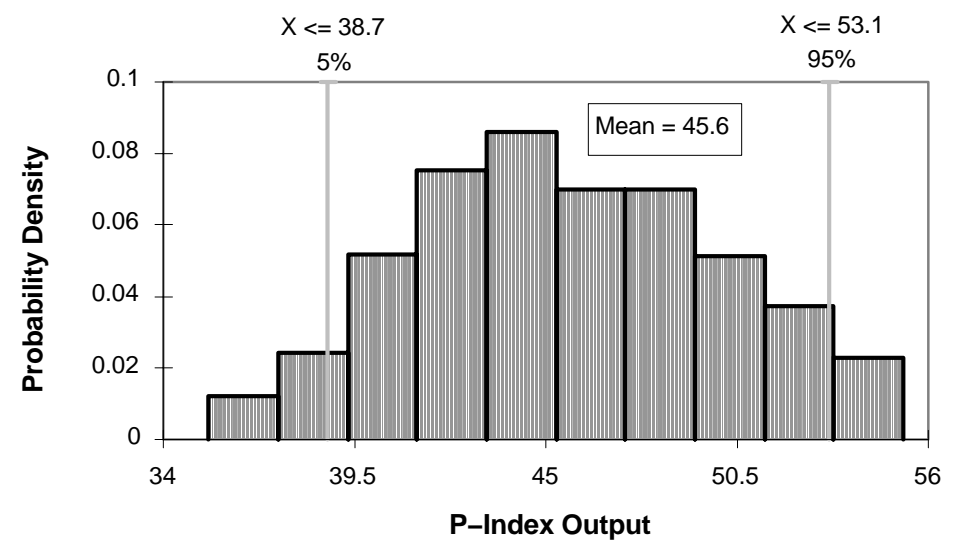

(b) Medium P risk

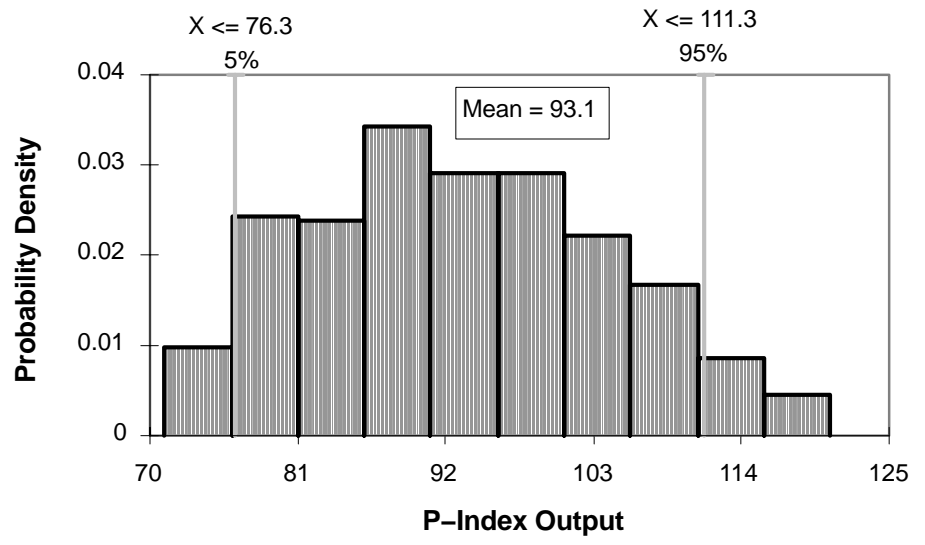

(c) High P risk

Figure 7. Probability density functions of the P-Index for the Ridge and Valley risk scenarios.

As discussed earlier, errors or lack of consistency in recommended $\mathrm{P}$ application rates can have significant impact on both the farmer and the regulator. To minimize unnecessary economic impact on farmers, for those cases that are near the threshold value, more careful measurements of those parameters subject to variability should be made to ensure that appropriate $\mathrm{P}$ recommendations are given.

\section{SUMMARY AND CONCLUSIONS}

The sensitivity analysis determined which parameters the P-Index was most sensitive to and provided an understanding of the strengths and weaknesses of the P-Index. Relative sensitivity results were more similar between the Ridge and Valley and Piedmont regions than with the Eastern Shore region due to similar baseline values within those regions. The P-Index was most sensitive in the low and medium scenarios to the management subfactors including annual application rate, method of fertilizer application, applied fertilizer DRP, and source availability factor. As erosion and runoff potential increased, the P-Index was most sensitive to the erosion risk factors including soil loss. Under conditions with subsurface leaching, the P-Index was most sensitive to the subsurface leaching factors and Mehlich I soil test P.

According to the analysis, variability of the most sensitive input parameters has a greater impact on the P-Index as risk 
level increases within each of the three regions. The Ridge and Valley region exhibited the greatest variability among the medium-risk scenarios. The probability distribution analysis showed the P-Index could have a range of values as a result of user and parameter variability with respect to Mehlich I P, soil loss, and distance to stream. Some of the resulting distributions of P-Index values spanned more than one P management category, especially at medium and high risk levels.

The deterministic method, used to calculate sensitivity, was a useful means to identify those parameters to which the P-Index value was most sensitive. Through this method, parameters were identified where improved estimation procedures are needed to improve consistency in P-Index values and their resulting $\mathrm{P}$ application recommendations. These parameters include the sediment and runoff delivery factors, and the association between runoff and the applied fertilizer DRP factor. Additional studies of these factors would be helpful in improving the Virginia P-Index.

The Latin hypercube random sampling method was an effective method for evaluating the sensitivity of the P-Index to those factors most subject to variability in estimation. Using this method, it was determined that a range of values for the P-Index could result. If the P-Index is near a threshold value, a more costly management recommendation than necessary might be given. Being in a different management category can have an economic impact for the farmer and an environmental and policy impact for the regulator. Thus, consistent, accurate estimates of soil loss are very important in reducing variability in the P-Index and its corresponding management recommendation. The methods applied in this study, although tailored to meet the objectives for the P-Index, could be used for evaluating other indexes as well.

\section{REFERENCES}

Andraski, T. W., L. G. Bundy, and K. C. Kilian. 2003. Manure history and long-term tillage effects on soil properties and phosphorus losses in runoff. J. Environ. Qual. 32(5): 1782-1789.

Daniel, T. C., A. N. Sharpley, D. R. Edwards, R. Wedepohl, and J. L. Lemunyon. 1994. Minimizing surface water eutrophication from agriculture by phosphorus management. J. Soil Water Cons. 49(2, suppl.): 30-38.

Dickinson, R. P., and R. J. Gelinas. 1976. Sensitivity analysis of ordinary differential equation systems - A direct method. $J$. Computational Phys. 21(2): 123-143.

Gburek, W. J., A. N. Sharpley, L. Heathwaite, and G. J. Folmar. 2000. Phosphorus management at the watershed scale: A modification of the phosphorus index. J. Environ. Qual. 29(1): 130-144.

Hamby, D. M. 1994. A review of techniques for parameter sensitivity analysis of environmental models. Environ. Mont. and Assess. 32(2): 135-154.

Helton, J. C., R. L. Iman, and J. B. Brown. 1985. Sensitivity analysis of the asymptotic behavior of a model for the environmental movement of radionuclides. Ecol. Modelling 28(3): 243-278.

Hoffman, F. O., and R. H. Gardner. 1983. Evaluation of uncertainties in environmental radiological assessment models. In Radiological Assessments: A Textbook on Environmental Dose Assessment, 11-1 to 11-55. Report No. NUREG/CR-3332. J. E. Till and H. R. Meyer, eds. Washington, D.C.: U.S. Nuclear Regulatory Commission.

Jacomino, V. M. F., and D. E. Fields. 1997. A critical approach to the calibration of a watershed model. J. American Water Res. Assoc. 33(1): 142-154.
James, L. D., and S. J. Burges. 1982. Chapter 11: Selection, calibration, and testing of hydrologic models. In Hydrologic Modeling of Small Watersheds, 437-470. St. Joseph, Mich.: ASAE.

Lemunyon, J. L., and R. G. Gilbert. 1993. Concept and need for a phosphorus assessment tool. J. Production Agric. 6(4): 483-496.

Mehlich, A. 1953. Determinations of $\mathrm{P}, \mathrm{Ca}, \mathrm{Mg}, \mathrm{K}, \mathrm{Na}$, and $\mathrm{NH}_{4}$ by North Carolina soil testing laboratories. Mimeograph. Raleigh, N.C.: North Carolina Department of Agriculture.

Morisawa, S., and Y. Inoue. 1974. On the selection of a ground disposal site by sensitivity analysis. Health Phys. 26(3): 251-261.

Mullins, G., M. L. Wolfe, J. Pease, L. Zelanzy, L. Daniels, M. Beck, M. Brosius, A. Vincent, and D. Johns. 2005. Virginia Phosphorus Index: Version 1.3 Technical Guide. Blacksburg, Va.: Virginia Tech. Available at: http://p-index.agecon.vt.edu.

Palisade Corp. 2000. @Risk Version 4. Newfield, N.Y.: Palisade Corp.

Pautler, M. C. and J. T. Sims. 2000. Relationships between soil test phosphorus, soluble phosphorus, and phosphorus saturation in Delaware soils. SSSA J. 64(2): 765-773.

Pote, D. H., T. C. Daniel, A. N. Sharpley, P. A. Moore, D. R. Edwards, and D. J. Nichols. 1996. Relating extractable soil phosphorus losses in runoff. SSSA J. 60(3): 855-859.

Renard, K. G., and V. A. Ferreira. 1993. RUSLE model description and database sensitivity. J. Environ. Qual. 22(3): 458-466.

Roloff, G, R. De Jong, and M. C. Nolin. 1998. Crop yield, soil temperature, and sensitivity of EPIC under central-eastern Canadian conditions. Canadian J. Soil Sci. 78(3): 431-439.

Schmidt, J. R., R. K. Taylor, and G. A. Milliken. 2002. Evaluating the potential for site-specific phosphorus applications without high-density soil sampling. SSSA J. 66(1): 276-283.

Sharpley, A. N. 1995. Dependence of runoff phosphorus on extractable soil phosphorus. J. Environ. Qual. 24(5): 920-926.

Sharpley, A. N., S. J. Smith, O. R. Jones, W. A. Berg, and G. A. Coleman. 1992. The transport of bioavailable phosphorus in agricultural runoff. J. Environ. Qual. 21(1): 30-35.

Sharpley, A., S. C. Chapra, R. Wedepohl, J. T. Sims, T. C. Daniel, and K. R. Reddy. 1994. Managing agricultural phosphorus for the protection of surface waters: Issues and options. J. Environ. Qual. 21(1): 30-35.

Sharpley, A. N., J. L. Weld, D. B. Beegle, P. J. A. Kleinman, W. J. Gburek, P. A. Morroe, Jr., and G. Mullins. 2003. Development of phosphorus indices for nutrient management planning strategies in the United States. J. Soil Water Cons. 58(3): 137-152.

Storm, D. E., T. A. Dillaha, and S. Mostaghimi. 1986. Modeling phosphorus transport in surface runoff. Trans. ASAE 31(1): 117-127.

Tiscareno-Lopez, M. 1991. Sensitivity analysis of the WEPP watershed model. MS thesis. No. E9791 1991 718. Tucson, Ariz.: University of Arizona.

USDA-NRCS-VA. 1997. Revised Universal Soil Loss Equation (RUSLE), Technical Guide Erosion Prediction. Washington, D.C.: USDA Natural Resources Conservation Service, Virginia Implementation.

USDA-NRCS-VA. 2001. Virginia Conservation Practice Standard, Nutrient Management, Code 590. Field Office Technical Guide. Washington, D.C.: USDA-NRCS. Available at: www.nrcs.usda.gov/technical/efotg/.

USDA-SCS. 1994. The Phosphorus Index - A Phosphorus Assessment Tool, Water Resources/Water Quality Technical Note. No. 1901. Fort Worth, Texas: USDA-SCS South National Technical Center.

Walker, S. E., J. K. Mitchell, M. C. Hirschi, and K. E. Johnsen. 2000. Sensitivity analysis of the root zone water quality model. Trans. ASAE 43(4): 841-846. 
